Available online at Journal Website
https://ijma.journals.ekb.eg/
Main subject [Medicine]

Original article

\title{
Assessment of Anti-Streptolysin-0 Titre in Healthy School Age Children in El Behira Governorate
}

\author{
Mona Moustafa Ali Kordy[a]; Mohamed Abdel Salam Zannoun[a]; Magdy Zaki El Ghanam[b]
}

Department of Pediatrics, Damietta Faculty of Medicine, Al-Azhar University, Egypt [a].

Department of Clinical Pathology, Damietta Faculty of Medicine, Al-Azhar University, Egypt $[$ [b]

Corresponding author

Mona Moustafa Ali Kordy

Email: monamoustafa454@gmail.com

\section{ABSTRACT}

Background: Group-A streptococcal serology is used for post-streptococcal disease diagnoses, such as acute rheumatic fever, and occasionally for diagnosis of streptococcal pharyngitis. The prevalence of rheumatic fever in school children aged 6 to 15 years ranges between 0.2 to 0.75 per 1000 children per year. The prevalence of rheumatic heart disease in 1000 children ranges from 1 to 5.4 .

Aim of the work: To determine upper limit of the normal range of Antistreptolysin 0 titre in healthy school children, aged 6-15 years old in El Behira governorate.

Patients and Methods: A cross-sectional study had been performed in EL Behira Governorate and the collected sample were tested in clinical pathology Lab [Al-Azhar University Hospital, Damietta]. A total of 3000 [1609 Males, 1391 Females] serum samples had been collected from children aged 6-15 years, had been tested for Anti-streptolysin 0 titer [ASO] by turbidimetry.

Results: Normal value for the ASO titer rose sharply during early childhood and then declined gradually with age. The estimated titer that was $80 \%$ of the upper limit or normal at age 10 years was $287 \mathrm{IU} / \mathrm{ml}$ for ASO.

Conclusion: This study provides the upper limit of normal value for ASO titre of school children. The "more than 400" rating should instruct clinicians in the treatment of post-streptococcal diseases in patients and provide valuable longitudinal evidence for potential intervention trials against streptococcal diseases in group A.

Keywords: Group A Streptococci; Anti-streptolysin O; Upper limit of normal; Children; El Behira.

This is an open access article under the Creative Commons license [CC BY] [https://creativecommons.org/licenses/by/2.0/]

Please cite this article as: Kordy MMA, Zannoun MA, El Ghanam MZ. Assessment of Anti-Streptolysin-0 Titre in Healthy School Age Children in El Behira Governorate. IJMA 2020; 2[3]: 625-630.

\footnotetext{
${ }^{*}$ Main subject and any subcategories have been classified according to the research topic.
} 


\section{INTRODUCTION}

Group A Streptococcus [GAS] is synonymous with Streptococcus pyogenes, the only species of $\beta$ hemolytic streptococci within this group. GAS is one of the leading pathogenic bacteria that infects children and adolescents, and is associated with a wide range of disease and infection states. Worldwide $>600$ million cases of GAS pharyngitis and $>100$ million cases of GAS pyoderma are estimated annually[1]. The most serious complication of GAS is acute rheumatic fever [ARF] and rheumatic heart disease. While ARF is relatively rare in developed economies, it is much more common in developing countries and among native peoples ${ }^{[2]}$. Anti-Streptolysin $O$ [ASO] is the antibody made against streptolysin 0 , an immunogenic, oxygenlabile hemolytic toxin that is produced by most group$A$ strains and many group $C$ and $G$ streptococci strains. The $O$ in the name is Oxygen-labile; the other related toxin is Streptolysin-S oxygen-stable. The main function of streptolysin $\mathrm{O}$ is in particular to induce hemolysis [the free splitting of red blood cells], beta-hemolysis[3].

Determination of the upper normal limit of ASO titer is a crucial step to determine the cutoff point at which, physicians must initiate the therapy for group A streptococci to avoid its associated potential complications.

\section{AIM OF THE WORK}

The objective of this study was to determine upper limit of normal range of Anti streptolysin-O titre in healthy school children [6-15 years old] in EL Behira governorate.

\section{PATIENTS AND METHODS}

A cross-sectional study was carried out in El Behira Governorate and the collected samples were tested in Clinical Pathology Labo at Al-Azhar University Hospital [Damietta] from December 2018 till December 2019. A total of 3000 [1609 Males, 1391 Females] serum samples had been collected and tested for Anti-streptolysin $\mathrm{O}$ titer [ASO] and turbidimetry can be measured. The study was carried out in compliance with the Code of Ethics [Helsinki Declaration] of the International Medical Association for Human Studies.

Data collection: A complete medical history has been taken and the findings recorded in a pre- designed questionnaire. The data collected included name, age at study time, sex, residence and antibiotic usage etc. Additionally, for each subject, the body weight and length were measured.

Exclusion criteria were: echocardiogram-proven rheumatic heart disease [because these subjects are at a higher risk of acute rheumatic fever at any time]; recent GAS pharyngitis; and any evidence of impetigo, temperature of $>38^{\circ} \mathrm{C}$ on the day of enrollment.

Laboratory investigations including: Antistreptolysin 0 titer [ASO], which had been determined by latex agglutination method. Reference values for adults $<200 \mathrm{IU} / \mathrm{mL}$, and for children $<150 \mathrm{IU} / \mathrm{mL}$

Statistical Analysis: Information was fed to the machine using version 20.0 of the IBM SPSS software package. Qualitative information was represented using number and percent. Chi-square test was used to assess similarity between different groups over categorical variables. The findings of the significatory test are reported as two-tailed odds. The importance of the results obtained was calculated at the point of 5 per cent. Chi-Square tests the association between qualitative nominal variables, it is performed mainly on frequencies. This determines whether the frequencies measured differ significantly from the frequencies predicted.

\section{RESULTS}

The distribution of the studied group regarding their age and sex, is presented in table [1]. There were 1609 males (53.6\%) and 1391 females $(46.4 \%)$. The most common age group of males were those 12 to $<14$ years $(25.5 \%)$, while in females, it was 8 to $<10$ yeas $(27.8 \%$ ), with no significant difference between males and females

The the majority of the studied group had ASO titer in range 101-300 [34.8\%], followed by range 50$100[26.0 \%]$, the subjects with ASO titer $>400$ were 192 cases [6.4\%]. The overall range of ASO titer was $7-478$ with mean $167.0 \pm 125.1$, the median was 125 [Table 2]

The relation between ASO titer and age of children: it was found that there was no significant association between the ASO titer and age group, although high ASO titer increased in age group > 10 yeas but this increase was insignificant [Table 3]. 
However, there was a significant association between the socioeconomic status and ASO titer, the high level of ASO titer were related with low socioeconomic status [ $p<0.05$ ] [Table 4]. between the high level of ASO titer and the number of acute follicular tonsillitis per year. All children with high ASO titer $>400$ had at least two or more times of attacks per year [Table 5]

In addition, there was a highly significant relation

Table [1]: Distribution of the studied group regarding their demographic data.

\begin{tabular}{|c|c|c|c|c|c|c|}
\hline \multirow{2}{*}{ Age group } & \multicolumn{2}{|c|}{ Male } & \multicolumn{2}{|c|}{ Female } & \multicolumn{2}{|c|}{ Total } \\
\hline & $\mathbf{N}$ & $\%$ & $\mathrm{~N}$ & $\%$ & $\mathrm{~N}$ & $\%$ \\
\hline $6-<8$ years & 217 & 13.5 & 303 & 21.8 & 520 & 17.3 \\
\hline $8-<10$ & 365 & 22.7 & 387 & 27.8 & 752 & 25.1 \\
\hline $10-<12$ & 410 & 25.5 & 298 & 21.4 & 708 & 23.6 \\
\hline $12-<14$ & 362 & 22.5 & 248 & 17.8 & 610 & 20.3 \\
\hline $14-15$ & 255 & 15.8 & 155 & 11.1 & 410 & 13.7 \\
\hline Total & 1609 & 53.6 & 1391 & 46.4 & 3000 & 100.0 \\
\hline $\begin{array}{l}X^{2} \\
P\end{array}$ & & & & & & \\
\hline
\end{tabular}

Table [2]: Distribution of the studied group regarding the level of ASO titer.

\begin{tabular}{|l|c|c|}
\hline \multicolumn{1}{|c|}{ ASO titer } & Number & Percent \\
\hline$<50$ & 600 & 20.0 \\
\hline $\mathbf{5 0 - 1 0 0}$ & 780 & 26.0 \\
\hline $\mathbf{1 0 1 - 3 0 0}$ & 1044 & 34.8 \\
\hline $\mathbf{3 0 1 - 4 0 0}$ & 384 & 12.8 \\
\hline$>\mathbf{4 0 0}$ & 192 & 6.4 \\
\hline Range & & \\
Mean & & $7-478$ \\
S.D. & 167.0 & \\
Median & 125.1 & \\
\hline
\end{tabular}

Table [3]: Relation between ASO titer and age of children.

\begin{tabular}{|c|c|c|c|c|c|c|c|c|c|c|c|c|}
\hline \multirow{3}{*}{ Age group } & \multicolumn{10}{|c|}{ ASO titer } & \multirow{2}{*}{\multicolumn{2}{|c|}{ Total }} \\
\hline & \multicolumn{2}{|c|}{$<50$} & \multicolumn{2}{|c|}{$50-100$} & \multicolumn{2}{|c|}{$101-300$} & \multicolumn{2}{|c|}{$301-400$} & \multicolumn{2}{|c|}{$>400$} & & \\
\hline & No. & $\%$ & No. & $\%$ & No. & $\%$ & No. & $\%$ & No. & $\%$ & No. & $\%$ \\
\hline $6-<8$ years & 145 & 24.2 & 158 & 20.3 & 105 & 10.1 & 104 & 27.1 & 8 & 4.2 & 520 & 17.3 \\
\hline $8-<10$ & 69 & 11.5 & 254 & 32.6 & 325 & 31.1 & 85 & 22.1 & 19 & 9.9 & 752 & 25.1 \\
\hline $10-<12$ & 125 & 20.8 & 133 & 17.1 & 314 & 30.1 & 88 & 22.9 & 48 & 25.0 & 708 & 23.6 \\
\hline $12-<14$ & 105 & 17.5 & 168 & 21.5 & 205 & 19.6 & 75 & 19.5 & 57 & 29.7 & 610 & 20.3 \\
\hline $14-15$ & 156 & 26.0 & 67 & 8.6 & 95 & 9.1 & 32 & 8.3 & 60 & 31.3 & 410 & 13.7 \\
\hline Total & \multicolumn{2}{|c|}{600} & \multicolumn{2}{|c|}{780} & \multicolumn{2}{|c|}{1044} & \multicolumn{2}{|c|}{384} & \multicolumn{2}{|c|}{192} & 3000 & 100 \\
\hline $\begin{array}{l}X^{2} \\
p\end{array}$ & & & & & & & & & & & & \\
\hline
\end{tabular}

Table [4]: Relation between ASO titer and socioeconomic status

\begin{tabular}{|c|c|c|c|c|c|c|c|c|c|c|c|c|}
\hline \multirow{3}{*}{ Socioeconomic status } & \multicolumn{10}{|c|}{ ASO titer } & \multirow{2}{*}{\multicolumn{2}{|c|}{ Total }} \\
\hline & \multicolumn{2}{|c|}{$<50$} & \multicolumn{2}{|c|}{$50-100$} & \multicolumn{2}{|c|}{$101-300$} & \multicolumn{2}{|c|}{$301-400$} & \multicolumn{2}{|c|}{$>400$} & & \\
\hline & No. & $\%$ & No. & $\%$ & No. & $\%$ & No. & $\%$ & No. & $\%$ & No. & $\%$ \\
\hline Low & 69 & 11.5 & 168 & 21.5 & 625 & 59.9 & 124 & 32.3 & 134 & 69.8 & 1120 & 37.3 \\
\hline Middle & 185 & 30.8 & 389 & 49.9 & 204 & 19.5 & 231 & 60.2 & 41 & 21.4 & 1050 & 35 \\
\hline High & 346 & 57.7 & 223 & 28.6 & 215 & 20.6 & 29 & 7.6 & 17 & 8.9 & 830 & 27.7 \\
\hline Total & \multicolumn{2}{|c|}{600} & \multicolumn{2}{|c|}{780} & \multicolumn{2}{|c|}{1044} & \multicolumn{2}{|c|}{384} & \multicolumn{2}{|c|}{192} & 3000 & 100 \\
\hline $\begin{array}{l}X^{2} \\
p\end{array}$ & \multicolumn{10}{|c|}{$\begin{array}{c}22.5 \\
0.0001^{*}\end{array}$} & & \\
\hline
\end{tabular}


Kordy MMA, et al.

Table [5]: Relation between ASO titer and number of attacks of acute follicular tonsillitis per year

\begin{tabular}{|c|c|c|c|c|c|c|c|c|c|c|c|c|}
\hline \multirow{3}{*}{$\begin{array}{c}\text { Number of attacks of acute follicular } \\
\text { tonsillitis per year }\end{array}$} & \multicolumn{10}{|c|}{ ASO titer } & \multirow{2}{*}{\multicolumn{2}{|c|}{ Total }} \\
\hline & \multicolumn{2}{|c|}{$<50$} & \multicolumn{2}{|c|}{$50-100$} & \multicolumn{2}{|c|}{$101-300$} & \multicolumn{2}{|c|}{$301-400$} & \multicolumn{2}{|c|}{$>400$} & & \\
\hline & No. & $\%$ & No. & $\%$ & No. & $\%$ & No. & $\%$ & No. & $\%$ & No. & $\%$ \\
\hline 0 & 452 & 75.3 & 201 & 25.8 & 321 & 30.7 & 187 & 48.7 & 0 & 0.0 & 1161 & 38.7 \\
\hline 1 & 105 & 17.5 & 375 & 48.1 & 241 & 23.1 & 131 & 34.1 & 0 & 0.0 & 852 & 28.4 \\
\hline 2 & 43 & 7.2 & 186 & 23.8 & 198 & 19.0 & 52 & 13.5 & 19 & 9.9 & 498 & 16.6 \\
\hline 3 & 0 & 0.0 & 18 & 2.3 & 268 & 25.7 & 13 & 3.4 & 66 & 34.4 & 365 & 12.2 \\
\hline 4 & 0 & 0.0 & 0 & 0.0 & 16 & 1.5 & 1 & 0.3 & 107 & 55.7 & 124 & 4.1 \\
\hline Total & \multicolumn{2}{|c|}{600} & \multicolumn{2}{|c|}{780} & \multicolumn{2}{|c|}{1044} & \multicolumn{2}{|c|}{384} & \multicolumn{2}{|c|}{192} & 3000 & 100 \\
\hline $\begin{array}{c}X^{2} \\
p\end{array}$ & \multicolumn{10}{|c|}{$\begin{array}{r}28.9 \\
0.001^{*}\end{array}$} & & \\
\hline
\end{tabular}

\section{DISUCSSION}

Worldwide, 15.6 million people have rheumatic heart disease [RHD]. The Middle East, the Indian subcontinent and some parts of Africa and South America are of major public health concern. The prevalence of RHD among school children in Egypt was stated to be 5.1 per 1000 . Furthermore, the course of ARF has been found to be severe and aggressive in various parts of the country where rheumatic fever is still one of the major public health problems in Egypt [4].

It is understood that ASOT's Upper Limit of Normal [ULN] values often vary with respect to different geographic areas, seasons and infection sites. Since over diagnosis of ARF based on a raised ASOT is not uncommon, interpreting ASO titers in patients suspected of having ARF is important for the ULN value of ASO in normal children[5],

Most of these values reached the normal assay average of $200 \mathrm{IU} / \mathrm{ml}$. Due to the frequent, mostly untreated; streptococcal infection in our population, the ULN in our sample was even higher hitting $398.5 \mathrm{IU} / \mathrm{ml}$. Therefore, there may be significant differences in antibody titers for distinct groups in specific geographic areas. This may be due to each locality's climatic or socioeconomic conditions ${ }^{[6]}$.

The results of our study showed that there was no significant difference between age distributions in relation to the sex in the studied group. There was 1609 male [53.6\%] and 1391 [46.4\%] females, the distribution of age group among the two sex groups was symmetrical without significant difference, this results was important to insure that the sample was homogenous and normally distributed regarding demographic data.
This study showed that the ASO titer ranged from $7-478 \mathrm{IU} / \mathrm{ml}, 80.0 \%$ of the studied children had ASO less than 300 , while 384 cases had ASO titer between 301-400, it was found that 192 cases had ASO titer more than $400 \mathrm{IU} / \mathrm{ml}$. the most frequent ASO titer group was 101-300 this group included 1044 child [34.8\%]. These results agree with study carried out by Khaled et al.[7]; they investigate the ASO titre, and found that for total subjects, the ASO ULN serum level was $276.2 \mathrm{IU} / \mathrm{ml}$, with a mean of $195 \mathrm{IU} / \mathrm{ml}$. For children 9-10 years [299 IU/ml], and [244.8 IU/ml] for children 5-6 years old, followed by $264.7 \mathrm{IU} / \mathrm{ml}$ for children aged $7-8$ years ${ }^{[7]}$.

Steer et al. ${ }^{[8]}$ demonstrated the normal ranges of the ASO titer in all age groups in a Pacific island country. A total of 424 serum samples from people of all ages [with a sample enriched for school-aged children] were tested for their ASO titer. Normal value for the ASO titer rose sharply during early childhood and then declined gradually with age. The estimated titer that was $80 \%$ of the upper limit or normal at age 10 years were $287 \mathrm{lU} / \mathrm{ml}$ for ASO.

Kotby et al.[4] determined ASOT in normal children and in those with rheumatic fever and tonsillitis and studied the variation of ASOT with age and season. 660 children were recruited and classified as: group 1 [control group, $n=200$ healthy children], group 2 [ $n=20$ with ARF 1 st attack], group 3 [ $n=40$ with recurrent ARF], group 4 [ $n=100$ with RHD on Long Acting Penicillin [LAP]], group 5 [ $n=$ 100 with acute follicular tonsillitis], and group 6 [ $n=$ 200 healthy children with history of repeated follicular tonsillitis more than three times a year]. Serum ASOT was measured by latex agglutination. They reported that, ASOT was significantly higher in children $>10$ years of age, during winter and in those with acute RHD. Egyptian children have high ULN 
ASOT reaching $400 \mathrm{IU}$.

In the current work, the relation between ASO titer and age of children showed that there was no significant association between the ASO titer and age group, although the subject with high ASO titer was increased in age group more than 10 but this increase was insignificant [ $p>0.05]$. In agreement with this result, Gerber et al.[9] found no association between the increase in the levels of ASOT and age of children.

In contrast, Danchin et al.,[10] reported the results of a study of children aged 4-14 years that provides a local reference range for ASO titer for children in urban Australia. They found that, the mean titer of ASO in children over ten years of age $[320 \mathrm{IU} / \mathrm{ml}]$ was significantly lower than those between five and ten years, although it was higher than those below five years and could lead to substantial over diagnosis of recent $\mathrm{S}$. pyogenes infections.

Kotby et al.[4] stated that basal levels of ASOT increase with age but the pattern of increase during infection is not age dependent.

In this study, there were highly significant correlations between number of attacks of acute follicular tonsillitis and ASO titer level and age groups and there was a significant correlation between number of attacks of acute follicular tonsillitis and social classes.

We expressed the value of ASOT in terms of upper limit rather than as mean to show the highest acceptable value in this study with previous infection these children are normal and had no complaint at the time of sampling. Re-infection usually results in sustained or continuously rising titers, and it is known from experimental studies that antibody responses are more impressive on repeated exposure [11].

These results agree with study carried out by Sanjeevaiah et al., [12]; they investigate the upper limits of normal values of antistreptolysin ' $O$ ' Titers in normal healthy school going children of 6-16 years, they found that there was a significant increase of ASO titer in rural area and in low socioeconomic group. The comparison between the lower and higher socioeconomic classes with in the age group of 5 to 10 years. The GMT is $357 \mathrm{lU} / \mathrm{ml}$ among low socioeconomic group and $242 \mathrm{IU} / \mathrm{ml}$ among high socioeconomic group. The ULN is found to be 210 $\mathrm{IU} / \mathrm{ml}$ among low socioeconomic group and it is 225
IU/ml among high socioeconomic group. The difference observed is not statistically significant. The ASO titer seems to be influenced by various demographic factors like age, environmental factors, leading on to wide range of titer values, observed from different studies globally[12].

It has also been reported that the upper limit of normal titer varies over a period, even within the same geographical area. All these facts necessitate to define the upper limit of normal for individual population, as well as to be confirmed periodically to observe any change in the value to higher or lower side [12].

Conclusion: This study provides the upper limit of normal value of ASO titre for children of the school age. This value "more than 400 " will guide clinicians, when they will consider the diagnosis of post streptococcal diseases in patients and will provide useful baseline data for future studies of intervention against group A streptococcal diseases. Thus, the ASO test should be considered for any streptococcal-like diseases. This will also help in early prevention and treatment of rheumatic heart disease, decreasing morbidity and mortality of cardiovascular disorders.

\section{Financial and Non-Financial Relationships and Activities of Interest}

None

\section{REFERENCES}

1- Pontin IP, Sanchez DC, Di Francesco R. Asymptomatic Group A Streptococcus carriage in children with recurrent tonsillitis and tonsillar hypertrophy. Int $\mathrm{J}$ Pediatr Otorhinolaryngol. 2016; 86:57-59. [DOI: 10. 1016/j.ijporl. 2016. 03.044].

2- Carapetis JR, Beaton A, Cunningham MW, Guilherme L, Karthikeyan G, Mayosi BM, Zühlke L. Acute rheumatic fever and rheumatic heart disease. Nat Rev Dis Primers, 2016; 2[1], 1-24. [DOI:10.1038/ nrdp. 2015.84].

3-Blyth C. Robertson P. Anti-streptococcal antibodies in the diagnosis of acute and poststreptococcal disease: streptokinase versus streptolysin $O$ and deoxyribonuclease B. Pathology. 2016; 38[2]: 152-15. [DOI: 10. 1080/ 00313020600557060].

4-Kotby AA, Habeeb NM, El-Arab SE. Antistreptolysin O titer in health and disease: Levels and significance. Pediatrics Reports; 4: e8. Lancet 2012; 336:1167-71. [DOI:10. 4081/ pr.2012.e8].

5- Saini N, Kumar D, Swarnim S, Bhatt D, Kishore S. Comparison of antistreptolysin $\mathrm{O}$, anti-deoxy-ribonucleic B. titers in healthy children to those with acute pharyngitis, acute rheumatic fever, and rheumatic heart disease aged 5-15 years. Ann Pediatr Card. 2019; 12:195-200. [DOI: 10.4103/ apc.apc-60-18]. 
6- Nava A, del Rio C, Elena L, Aguilar CM, Mazariegos GR, Navarro SN, Reyes PA. Serum levels of antistreptolysin $O$ in teenagers from Mexican urban and rural areas. Revista Alergia México, 2008; 55[5]: 196-200. [DOI: 10.29262/ram.v65i3.355].

7- Khaled A, Hassan A. Anti Streptolysin O. normal values for healthy children aged from 5 to 15 years old in Sana'a City-Yemen. Annals Clin Lab Res. 2015; [3]. 1:1. [DOI: 10.21767/2386-5180.10001].

8- Steer AC, Law I, Matatolu L, Beall BW, Carapetis JR. Global emm type distribution of group A streptococci: systematic review and implications for vaccine development. Lancet Infect Dis. 2009 Oct;9[10]:611-6. [DOI: 10.1016/S1473-3099[09]70178-1].

9- Gerber MA, Baltimore RS, Eaton CB, Gewitz M, Rowley AH, Shulman ST, Taubert KA. Prevention of rheumatic fever and diagnosis and treatment of acute Streptococcal pharyngitis. Circulation 2009; 119[11]: 1541-51. [DOI: 10.1161/ Circulationaha.109.191959].
10- Danchin MH, Carlin JB, Devenish W, Nolan TM, Carapetis JR. New normal ranges of antistreptolysin 0 and antideoxyribonuclease B titres for Australian children. J Paediatr Child health 2005; 41[11]: 5836. [DOI: 10.1111/j.1440-1754. 2005.00726.x].

11- Shet A, Kaplan EL. Clinical use and interpretation of group A streptococcal antibody tests: A practical approach for the paediatrician or primary care physician. Pediatr Infect Dis J. 2002; 21: 420-6. [DOl: 10.1097/00006454200205000-00014].

12- Sanjeevaiah CR. Ahamed M, Mariyappa BD. Prediction of Upper Limits of Normal Values of Anti Streptolysin 'O'Titres in Normal Healthy School Going Children of 616 Years. Am J Pediatr. 2019;5[2],74-7. [DOI: 10.11648/j.ajp.20190502.17]. 